\title{
Broadband acoustic backscatter from crude oil under laboratory-grown sea ice
}

\author{
Christopher Bassett, ${ }^{\text {a) }}$ Andone C. Lavery, and Ted Maksym \\ Department of Applied Ocean Physics and Engineering, Woods Hole Oceanographic Institution, Woods Hole, \\ Massachusetts 02543, USA \\ Jeremy P. Wilkinson \\ British Antarctic Survey, High Cross Madingley Road, Cambridge, CB3 OET, United Kingdom
}

(Received 11 February 2016; revised 1 September 2016; accepted 14 September 2016; published online 4 October 2016)

In ice-covered seas, traditional air-side oil spill detection methods face practical challenges. Conversely, under-ice remote sensing techniques are increasingly viable due to improving operational capabilities of autonomous and remotely operated vehicles. To investigate the potential for under-ice detection of oil spills using active acoustics, laboratory measurements of high-frequency, broadband backscatter $(75-590 \mathrm{kHz})$ from crude oil layers $(0.7-8.1 \mathrm{~cm})$ under and encapsulated within sea ice were performed at normal and $20^{\circ}$ incidence angles. Discrete interfaces (water-oil, oil-ice, and ice-oil) are identifiable in observations following oil injections under the ice and during the subsequent encapsulation. A one-dimensional model for the total normal incidence backscatter from oil under ice, constrained by oil sound speed measurements from $-10{ }^{\circ} \mathrm{C}$ to $20{ }^{\circ} \mathrm{C}$ and improved environmental measurements compared to previous studies, agrees well with preencapsulation observations. At $20^{\circ}$ incidence angles echoes from the ice and oil under ice are more complex and spatially variable than normal incidence observations, most likely due to interface roughness and volume inhomogeneities. Encapsulated oil layers are only detected at normal incidence. The results suggest that high-frequency, broadband backscatter techniques may allow under-ice remote sensing for the detection and quantification of oil spills. (C) 2016 Acoustical Society of America.

[http://dx.doi.org/10.1121/1.4963876]

[TFD]

Pages: 2274-2287

\section{INTRODUCTION}

A significant portion of the world's untapped and undiscovered reserves of gas and oil are believed to be in Arctic subsea deposits (Gautier et al., 2009). The reduction in summer sea ice extent (Cavalieri and Parkinson, 2012), coupled with technological advances in extraction techniques and economic and political factors may result in increased resource extraction in Arctic waters. Any expansion of hydrocarbon extraction or other activities (e.g., shipping) in the Arctic increases the risk of an oil spill. A particular concern is that an oil spill could occur under sea ice, complicating spill detection and remediation. Although the detection of oil spills under ice has been the focus of previous studies, most of these applied technologies deployed on or above the ice surface, which requires that the sensors penetrate through the ice and any snow cover (Wilkinson et al., 2013, and references therein). In recent years, the successful operation of underwater vehicles under sea ice cover (Wadhams et al., 2006; Kunz et al., 2009; Williams et al., 2015) has increased interest in the viability of oil detection with sensor packages deployed below the ice.

\footnotetext{
${ }^{a}$ Current address: National Marine Fisheries Service, Alaska Fisheries Science Center, Resource Assessment and Conservation Engineering Division, 7600 Sand Point Way NW, Seattle, WA 98115. Electronic mail: chris.bassett@noaa.gov
}

Recent work has highlighted the potential for detecting thin oil layers trapped beneath sea ice using acoustic backscatter techniques (Bassett et al., 2014, 2015; Wilkinson et al., 2015). This study builds on this work by further examining the use of high-frequency $(f>50 \mathrm{kHz})$ broadband acoustic backscatter techniques. To understand acoustic backscatter from oil and ice, it is important to first understand what sea ice "looks" like acoustically. The important scattering features, which are related to the sea ice morphology, include the sound speed and density structure of the ice and the roughness at acoustically relevant scales.

Ice growth below a consolidated ice sheet takes the form of congelation ice, also referred to as columnar ice, which constitutes a majority of a first year ice pack. Congelation ice forms as an ice sheet grows downwards. Rather than forming a smooth ice-water interface, as sea ice freezes it forms a complex binary phase structure. As salt is rejected during freezing of the pure ice, a morphological instability develops, and the ice interface develops a fine-scale corrugated structure of parallel dendrites (up to $1 \mathrm{~cm}$ long and $<1 \mathrm{~mm}$ wide) that trap brine within the grooves. This complex zone near the base of the ice where the dendrites are present and the porosity is relatively high is referred to as the skeletal layer (Weeks, 2010). As downward growth of the ice continues, these dendrites pinch off and a complex brine network forms within the ice, including isolated brine pockets, interconnected channels, and vertical tubes through which cold, dense brine can drain into the seawater below. Due to the 
temperature-controlled freezing point of the brine and brine drainage from the ice, this network varies from the regular, porous structure in the skeletal layer to a complex network of less connected brine pockets and channels higher up in the ice (e.g., Weeks, 2010). Although alignment of the dendrites in the skeletal layer is regular within individual ice crystals, they are rarely aligned uniformly on larger scales (greater than a few centimeters) except in the presence of strong currents under shorefast ice (Weeks and Gow, 1978).

Previous work has identified and focused on two ways in which the properties and structure of sea ice contribute to the acoustic scattering. First, within the skeletal layer the bulk properties vary between those of seawater and the less porous sea ice above. This transition in the bulk acoustic properties results in a reflection coefficient that decreases with increasing frequency until reaching an asymptotic regime $(f>150 \mathrm{kHz})$ where the reflection coefficient is attributed to the acoustic impedance mismatch at the waterice interface (Garrison et al., 1991; Williams et al., 1992; Winebrenner, 1992; Mourad and Williams, 1993). The complex structure of the skeletal layer and dendrites also plays an important role in the observed backscatter from sea ice. Stanton et al. (1986) analyzed echo statistics from laboratory grown sea ice, fitting Rice probability density functions (PDFs) to the observations. For an acoustically smooth surface the Rice PDF approaches a Gaussian distribution, while a rough surface, with no coherent echo contribution, results in a Rayleigh PDF (Rice, 1952). Stanton et al. (1986) showed that for frequencies below $200 \mathrm{kHz}$ the laboratorygrown sea ice was relatively smooth (near-Gaussian PDF), while for frequencies greater than $400 \mathrm{kHz}$ the ice was acoustically rough and the distributions approached Rayleigh PDFs. From these statistics a root-mean-square (rms) roughness of approximately $0.3 \mathrm{~mm}$ was inferred, a value consistent with the observed spacing between the dendrites in the experiment. Combining these results, it can be inferred that at frequencies where the ice appears acoustically smooth, the scattering is dominated by the coherent reflection resulting from the gradient of the acoustic properties within the skeletal layer, while at high frequencies the scattering is driven by a combination of the roughness and the impedance mismatch between the ice and the seawater.

The behavior of crude oil spilled under ice is controlled by a large number of factors including, but not limited to, the ice morphology, the current physical state of the ice (e.g., growth versus melt), and the properties of the oil. Assuming the oil is sufficiently "light," as is typical of most crude oils, a spill underwater will result in a buoyant plume that rises through the water column to the surface interface (water-air or water-ice) where boundary conditions determine further transport. A previous laboratory investigation of the behavior of oil spilled under unconsolidated ice crystals and small ice pans, known as frazil and pancake ice, shows that the absence of a consolidated surface permits the rapid upward transport of oil through the ice layer followed by lateral spreading along the ice-air interface (Wilkinson et al., 2014). Under such circumstances, the oil layer is difficult to identify acoustically (Bassett et al., 2014) but has a visual surface expression (Wilkinson et al., 2014).
When the surface ice layer is consolidated the upward transport of oil is limited to percolation through the brine channels, while lateral spreading occurs along the water-ice interface (Wadhams, 1976; Malcolm, 1979; Martin, 1979). Under "smooth" ice, the equilibrium thickness of oil is determined by small-scale under-ice topography and interfacial forces, resulting in thicknesses ranging from 0.5 to $2 \mathrm{~cm}$ or more (Keevil and Ramseier, 1975; Greene et al., 1977; Kovacs et al., 1981). Under natural ice cover variable snow loading and ice deformation produce more variable underice topography, providing natural catchments for oil. Based on investigations of under-ice topography, it is estimated that oil thicknesses could vary from equilibrium thicknesses under smooth ice to tens of centimeters or more under rough ice, but that oil would only be present under a fraction $(<10 \%)$ of the ice cover due to preferential spreading between interconnected depressions along areas of thinner ice (Wilkinson et al., 2007).

If a spill occurs during sea ice growth, the ice can form a lip around the oil layer, preventing further lateral spreading. Compared to the surrounding ice-free areas, the ice growth rate under the oil is reduced due to the increased thermal resistivity of the combined ice and oil layers (Lewis, 1976; Izumiyama, 2004). If sufficient heat transfer still occurs across the oil layer, ice eventually encapsulates the oil, forming an "oil sandwich" (NORCOR, 1975). Additional ice growth below the oil layer appears to be crystallographically disconnected from the ice above the oil. Percolation of the oil into the ice is limited to the skeletal layer and brine channels in low concentrations ( $<5 \%$ by vol.) within the bottom few centimeters of the ice when the ice cover is stable or growing (NORCOR, 1975; Karlsson et al., 2011). In contrast, during periods of melting upward transport of oil can occur through brine channels due to the increased porosity of the ice (NORCOR, 1975; Martin, 1979).

Previous studies have shown that both high-frequency narrowband (Wilkinson et al., 2015) and broadband (Bassett et al., 2014, 2015) acoustic backscatter techniques can detect a layer of crude oil under congelation ice in a controlled, laboratory setting. This work focuses on further investigating the applicability of high-frequency $(75-590 \mathrm{kHz})$ broadband acoustic scattering techniques for detecting and quantifying crude oil spills under growing congelation ice. Expanding on previous work, the analysis here includes multiple controlled oil injections representing a broader range of realistic oil thicknesses $(0.7-8.1 \mathrm{~cm})$ in addition to observations of nonnormal incidence broadband backscatter from ice and oil under ice. The oil injections were also sampled acoustically during the encapsulation process to investigate the feasibility of using high-frequency acoustic backscatter to identify encapsulated oil. To support the measurements and further development of a one-dimensional (1D) normal incidence model for oil under ice, a time-of-flight experiment to determine the temperature-dependent sound speed of the crude oil was also performed. Considerably more supporting information (e.g., environmental measurements, ice cores, video) is available to aid in the interpretation of results than was available in previous experiments focused on acoustic techniques for under-ice remote sensing of oil. 


\section{EXPERIMENTAL SETUP AND METHODS}

The measurements of high-frequency broadband acoustic scattering from laboratory-grown sea ice and crude oil were performed in the Ice Engineering Facility Test Basin at the Cold Regions Research and Environmental Laboratory (CRREL) in Hanover, NH. These acoustic measurements were performed as part of a larger project funded by the Arctic Oil Spill Response Technology Joint Industry Programme with the goal of enhancing knowledge and capabilities in the area of Arctic oil spill response through focused research in three areas: surface remote sensing, subsea remote sensing, and modeling to understand the potential sensor performance under field conditions. Sound speed measurements of oil versus temperature were performed in a cold room at Woods Hole Oceanographic Institution (WHOI) in Woods Hole, MA. All measurements discussed here were obtained between November 3, 2014 and January 23, 2015. The facilities, instrumentation, and processing techniques are described in Secs. II A-II F.

\section{A. Ice Engineering Facility Test Basin and oil injections}

The Ice Engineering Facility Test Basin at CRREL is $36.6 \mathrm{~m}$ long, $9.1 \mathrm{~m}$ wide, and $2.4 \mathrm{~m}$ deep (Fig. 1). It was subdivided into smaller areas $(2.5 \mathrm{~m} \times 3 \mathrm{~m})$, referred to here as "hoops," to perform multiple oil injections with different volumes of oil. These primary hoops were located along the long-axis of the tank. A vinyl-coated polyester curtain that hung deep enough to contain the oil within the hoop surrounded each injection area. Six total primary oil injections with different oil volumes were performed. Results from four representative injections are presented. Additional smaller $(1.5 \mathrm{~m} \times 1.5 \mathrm{~m})$ control hoops located off-axis were used to obtain ice cores to examine the physical properties of the ice.

A rail/cart system was used for sampling under the ice and oil injections (Fig. 2). The rails, which ran the length of

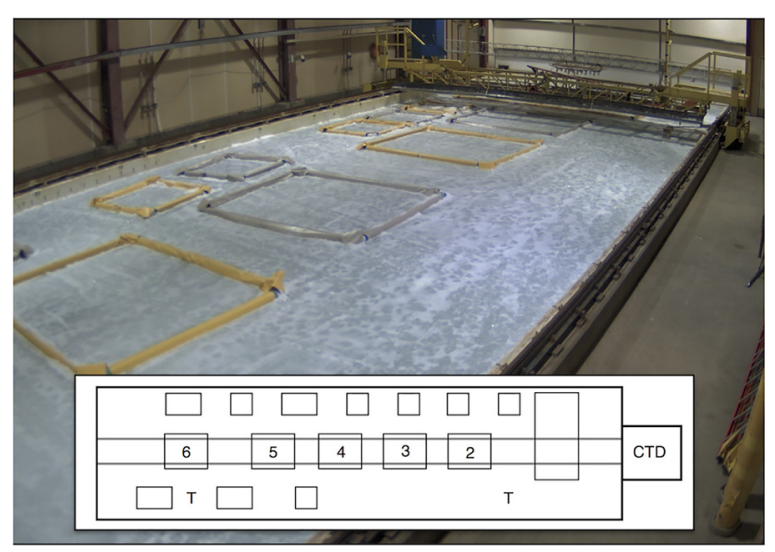

FIG. 1. (Color online) CRREL Ice Engineering Test Basin and the layout of the tank. The rectangles in the inset denote the approximate locations of individual hoops. The parallel lines spanning the length of the tank show the tracks for the underwater cart. The smaller hoops were used for ice cores. $\mathrm{T}$ denotes the locations of the thermistor strings. The preparation tank, which was isolated from the rest of the tank by a door and insulation (closed in photo; upper right) was used to remove the cart from the tank and to perform CTD casts.

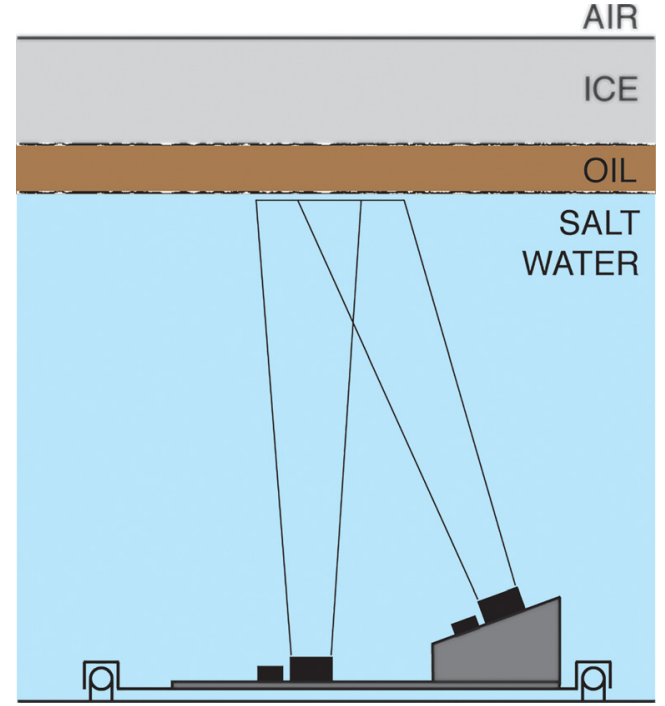

FIG. 2. (Color online) Design and orientation of the transducer mounting plates located on the cart for under-ice sampling. The transducer mounting plates (total dimensions: $76 \mathrm{~cm}$ wide and $18 \mathrm{~cm}$ tall), orientation, and transducer beams are drawn to scale. The total tank depth is $2.4 \mathrm{~m}$.

the tank, were leveled prior to the experiment. Movement of the cart was controlled by a chain drive and underwater servomotor driven by an air-side computer. Tests performed prior to the experiment showed that the location of the cart was controllable with centimeter-scale horizontal precision. An underwater pan/tilt/zoom video camera was mounted on the cart to visually monitor the oil injections, post-injection oil behavior, and ice growth.

For each oil injection multiple holes were drilled through the ice outside of the containment curtain immediately prior to the injection. A flexible hose attached to a pump and the oil storage container was lowered through one hole. Video cameras were lowered through the others to both record the oil injection and to determine the location of the hose outlet relative to the containment curtain. The oil for the injection was pumped from the storage containers at a low pressure to allow the oil to rise to the surface as a result of buoyancy. Care was taken to avoid introducing air under the hoop during the oil injection process. The oil used in all injections was an Alaskan North Shore crude with an American Petroleum Institute (API) gravity of $29.8^{\circ}$.

\section{B. Acoustic sampling}

To make measurements of the ice and oil prior to, during, and after the injections the rail/cart system was used to move the instruments to the desired location along the axis of the tank. A total of six transducers (mono-static operation) were mounted on the cart: three transducers (one of each frequency) at both normal $\left(0^{\circ}\right)$ and $20^{\circ}$ incidence angles. The transducers were custom Airmar Technology Corporation (Milford, NH) broadband transducers that transmitted one of three linear frequency-modulated signals $(75-130 \mathrm{kHz}$, $125-225 \mathrm{kHz}$, or $370-590 \mathrm{kHz}$ ) based on their nominal frequency (Table I). Throughout the experiment there was significant overlap between the transducer footprints. A custom 
TABLE I. Transducer and signal parameters. The footprint radius (normal incidence transducers) is calculated at $1.8 \mathrm{~m}$. All parameters are presented at the nominal frequency assuming a sound speed of $1437 \mathrm{~m} / \mathrm{s}$. The transmitted signals for all channels are $250 \mu$ s long.

\begin{tabular}{lccc}
\hline \hline & \multicolumn{3}{c}{ Frequency range $(\mathrm{kHz})$} \\
\cline { 2 - 4 } Operational parameter & $75-130$ & $115-225$ & $370-590$ \\
\hline Transducer notation & $\mathrm{B} 1_{\mathrm{N}}, \mathrm{B} 1_{\mathrm{O}}$ & $\mathrm{B} 2_{\mathrm{N}}, \mathrm{B} 2_{\mathrm{O}}$ & $\mathrm{B} 3_{\mathrm{N}}, \mathrm{B} 3_{\mathrm{O}}$ \\
Nominal frequency $[\mathrm{kHz}]$ & 100 & 160 & 500 \\
Wavelength $(\lambda)[\mathrm{cm}]$ & 1.44 & 0.90 & 0.29 \\
Transducer diameter $(D)[\mathrm{cm}]$ & 8.9 & 8.7 & 5.1 \\
Full beamwidth $(\theta)\left[{ }^{\circ}\right.$ at $\left.-3 \mathrm{~dB}\right]$ & 9.6 & 6.0 & 3.4 \\
Footprint radius $\left(r_{\mathrm{scat}} \tan [\theta / 2]\right)[\mathrm{cm}]$ & 15.1 & 9.4 & 5.3 \\
Bandwidth $(B)[\mathrm{kHz}]$ & 55 & 110 & 220 \\
Range resolution $\left(c_{\mathrm{w}} / 2 B\right)[\mathrm{cm}]$ & 1.3 & 0.7 & 0.4 \\
\hline \hline
\end{tabular}

Edgetech sonar system, described in detail in Lavery et al. (2010), operated the transducers from a pressure housing mounted on the cart. Modifications were made to each channel's amplifier to avoid saturating the received signals in the tank. The amplitudes of the transmitted signals were maintained at a constant level throughout the calibration and experiment. Specific channels are referenced by their bandwidth where B1, B2, and B3 refer to $75-130 \mathrm{kHz}$, $125-225 \mathrm{kHz}$, and $370-590 \mathrm{kHz}$, respectively. Each channel reference is accompanied by a subscript ${ }_{\mathrm{N}}$ or ${ }_{\mathrm{O}}$ for either normal or oblique incidence angles (e.g., the $75-130 \mathrm{kHz}$, normal incidence transducer is referred to as $\mathrm{B} 1_{\mathrm{N}}$ ).

The data presented here are derived from two types of measurements following four different oil injections (hoops 2, 4-6). First, time series sampling was performed prior to, during, and following oil injections to identify crude oil layers and to monitor the encapsulation process. During time series sampling the cart was located under the center of a hoop and the transducers pinged every $10 \mathrm{~s}$. The signal-tonoise ratio was sufficiently large during the experiment that little ping-to-ping variability was observed, obviating the need for further averaging. With the exception of periods when the cart was performing spatial sampling or was removed from the water the cart remained under the center of a hoop to obtain time series data. Second, spatial sampling was performed along the axis of the tank to obtain data from the ice and to map the spatial variability of the oil layers. During spatial sampling transects the ping rate on each channel was $7-10 \mathrm{~Hz}$ and velocity of the cart was $2 \mathrm{~m} / \mathrm{min}$. This speed corresponds to approximately $3.3-4.7 \mathrm{~mm} / \mathrm{ping}$ and results in significant overlap in the acoustic footprints (see Table I). Throughout the experiment the delay between pings on different channels was set to $20 \mathrm{~ms}$ to avoid crosstalk.

\section{Calibration}

To calibrate the pulse-echo system the air-water interface was used prior to the formation of ice. In the absence of significant surface disturbances (e.g., surface waves), reflections from the pressure-release air-water interface are phaseshifted replicas of the transmitted signals. Using the pressure-release interface for calibration accounts for the combined transmit and receive sensitivities in addition to any distortion of the signals introduced by the power electronics. Calibration measurements were performed after the tank was filled, cooled to a near freezing point, and the surface had settled. During calibration the oblique transducers were oriented normal to the surface. The received echoes during calibration were stable, suggesting minimal surface disturbances. Temporal domain calibration data were obtained by coherently averaging the compressed pulse output. Frequency-domain calibration curves were determined by taking the linear average of the spectra. Further processing of the acoustic backscatter data is described in Sec. II D and example curves from the calibration process are shown in Fig. 3.

\section{Acoustic data analysis}

\section{Temporal domain}

Backscatter measurements are analyzed using pulse compression techniques (Turin, 1960; Stanton et al., 1998; Chu and Stanton, 1998; Stanton et al., 2010). In comparison to traditional narrowband techniques, which have a temporal resolution proportional to the pulse length, broadband signals analyzed using pulse compression techniques have a temporal resolution proportional to $1 / B$, where $B$ is the bandwidth of the pulse (Chu and Stanton, 1998). The compressed-pulse output, which is obtained following Eq. (14) in Stanton et al. (1998) is presented here in terms of the compressed-pulse envelope, $E_{\mathrm{CP}}$.

Prior to the oil injection, the first significant echo in $E_{\mathrm{CP}}$ is associated with the water-ice interface, and the range to this interface is given by $r=\left(c_{\mathrm{w}} / 2\right) t$, where $c_{\mathrm{w}}$ is the sound speed of the water determined from conductivity, temperature, and depth (CTD) measurements and $t$ is the delay time to the first interface peak in $E_{\mathrm{CP}}$. Once injected, the buoyant oil forms a layer under the ice. When the oil layer is
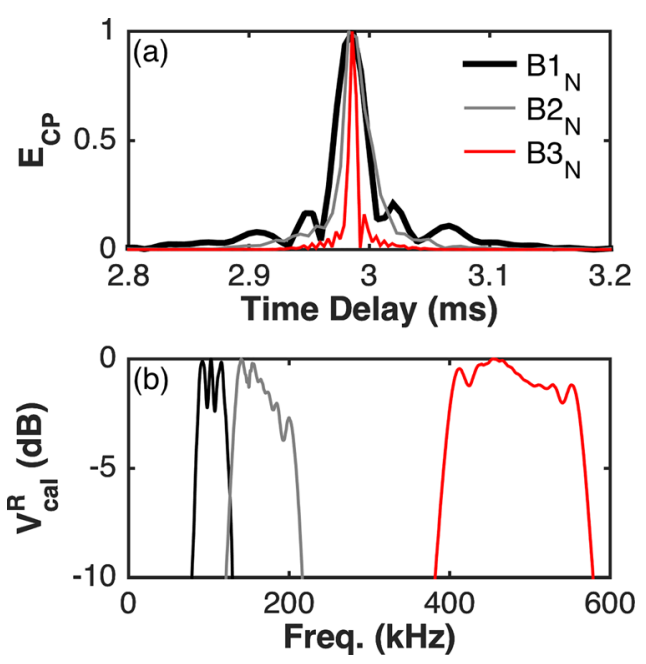

FIG. 3. (Color online) Calibration results from the pressure-release surface prior to ice formation. (a) Normalized $E_{\mathrm{CP}}$ for the three transducers. (b) Normalized calibration spectra for $\mathrm{B} 1_{\mathrm{N}}, \mathrm{B} 2_{\mathrm{N}}$, and $\mathrm{B} 3_{\mathrm{N}}$. 
sufficiently thick $E_{\mathrm{CP}}$ contains peaks from both the water-oil and oil-ice interfaces. The thickness of the oil is then given by

$$
h_{\mathrm{oil}}=\frac{c_{\mathrm{oil}}}{2}\left(t_{\mathrm{oil}, \text { ice }}-t_{\mathrm{w}, \mathrm{oil}}\right),
$$

where $c_{\text {oil }}$ is the sound speed of the oil, and $t_{\text {oil,ice }}$ and $t_{\mathrm{w}, \text { oil }}$ are the time delays that correspond to the peaks in $E_{\mathrm{CP}}$ associated with the oil-ice and water-oil interfaces, respectively. Additional lower amplitude peaks are often present and can be attributed to inhomogeneities within the oil and ice layers and the ice-air interface. During spatial sampling under oil injections an automated approach to inferring $h_{\mathrm{oil}}$ from $E_{\mathrm{CP}}$ is implemented. This approach searches for two peaks in the normalized autocorrelation of $E_{\mathrm{CP}}$ that had a prominence of greater than 0.05 relative to local minima. The time lags associated with these peaks are then applied to Eq. (1) to calculate the oil thickness. If two sufficiently prominent peaks are not present then it is assumed that no oil layer is present.

\section{Frequency domain}

Frequency-domain results are presented in terms of a ratio of the scattered pressure to the incident pressure field [modified form of Eq. (10) in DiPerna and Stanton (1991)]

$$
R_{P}(\omega)=\frac{P_{\mathrm{scat}}(\omega)}{P_{\mathrm{inc}}(\omega)}=\frac{V^{R}(\omega)}{V_{\mathrm{cal}}^{R}(\omega)} \frac{r_{\mathrm{scat}}}{r_{\mathrm{cal}}}
$$

where $\omega$ is the angular acoustic frequency, $P_{\text {scat }}$ is the amplitude of the scattered pressure, $P_{\text {inc }}$ is the amplitude of the incident pressure at the scattering interface, $r_{\text {scat }}$ is the range to the scattering interface, and $r_{\text {cal }}$ is the range to the pressure-release interface during calibration. $V^{R}(\omega)$ and $V_{\text {cal }}^{R}(\omega)$ are the absolute values of the Fourier transforms of the compressed-pulse time series and the compressed pulse calibration time series, respectively. A term accounting for the amplitudes of the transmitted signals is generally required, but, in this case, is not included because the same signals and power levels were used throughout the experiment. This equation, used in previous studies (Lavery and Ross, 2007; Bassett et al., 2014, 2015), accounts for the range dependence of the incident pressure but does not necessarily account for the range dependence of the scattered pressure. As a result, direct comparisons between $R_{P}$ at different ranges are only appropriate under some circumstances.

There are two limiting cases for the range dependence of the scattered pressure and therefore the direct comparisons between $R_{P}$. In the first case, the roughness (typically described by the rms surface height) of a scattering interface is small relative to the acoustic wavelength (i.e., $\lambda \ll h_{\mathrm{rms}}$ ) and the scattered pressure has a $1 / 2 r_{\text {scat }}$ range dependence. Such acoustically smooth interfaces result in a range independent $R_{P}$ that is analogous to a reflection coefficient. When an interface is not acoustically smooth a direct comparison of $R_{P}$ at different ranges may be inappropriate. Under these conditions the range dependence of the scattered pressure can be as large as $1 / r^{2}$. However, the limited ranges under consideration in this study $(1.6-2.2 \mathrm{~m})$ result in a maximum difference between the amplitude as presented and the limiting case with a $1 / r^{2}$ range dependence is approximately $2.4 \mathrm{~dB} . R_{P}$ is presented in log space and attenuation in the water has been accounted for following Francois and Garrison (1982a,b). Attenuation in the oil is neglected.

To obtain the backscatter spectrum the compressed-pulse output is time-gated to include any echoes associated with the water-ice, water-oil, or oil-ice interfaces, but not the iceair interface. For consistency, the same time gate was used for all channels throughout the experiment. As described in Sec. II E, the inclusion of multiple interfaces, if present, leads to a spectral structure that can be used to infer the range between the interfaces if the material properties are known (Stanton et al., 1994). The thickness is inferred from the spectra by identifying local minima at least $2 \mathrm{~dB}$ lower than the adjacent peaks. The mean difference in frequency between the nulls, $\overline{\Delta f}$, is calculated and the oil layer thickness is inferred according to $h_{\mathrm{oil}}=c_{\mathrm{oil}} / 2 \overline{\Delta f}$.

\section{E. Crude oil density and sound speed measurements}

The density and sound speed of the 2014 Alaska North Slope crude oil were measured to constrain the reflection coefficients at the water-oil and oil-ice interfaces. An analysis of the oil properties (e.g., density, viscosity, and pour point) was performed by SL Ross Environmental Research Ltd. Using an Anton-Paar (Ashland, VA) density meter (ATSM, 2011) the crude oil density was measured at two temperatures $\left(0{ }^{\circ} \mathrm{C}\right.$ and $\left.20{ }^{\circ} \mathrm{C}\right)$ when the oil was fresh (limited evaporation had occurred). Here our concern is with the density of the fresh oil given the limited air exposure prior to the injections.

To measure the sound speed of the oil versus temperature a small Delrin ${ }^{\circledR}$ tank (inner dimensions: $30.5 \mathrm{~cm} \times 5.1 \mathrm{~cm}$ $\times 5.1 \mathrm{~cm}$ ) was built [Fig. 4(a)]. A Panametrics (Olympus NDT Inc., Waltham, MA) Immersion Transducer (V318, $1.91 \mathrm{~cm}$ diam.) was mounted at each end of the tank. For the
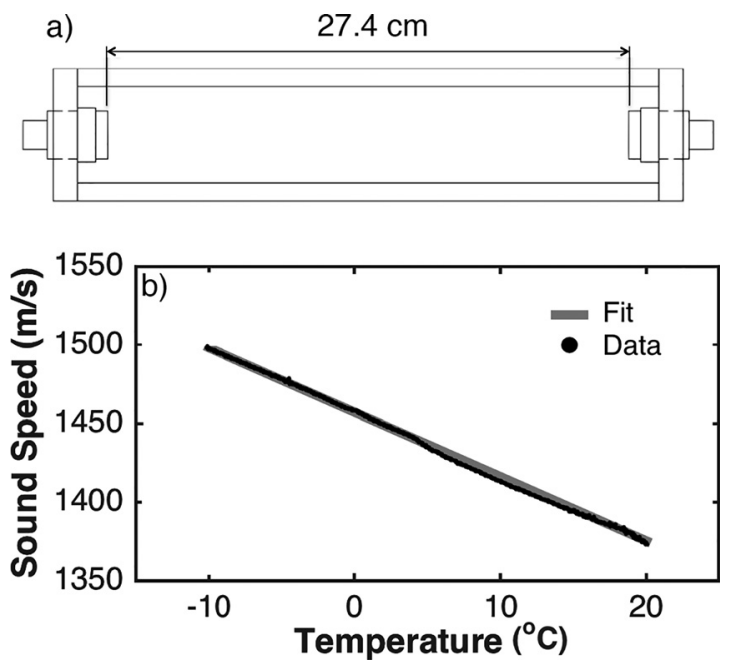

FIG. 4. (a) A plan view drawing of the sound speed measurement tank. The measured distance between the transducers is labeled. (b) The sound speed of the 2014 Alaskan North Slope crude oil versus temperature. A linear fit $\left(c_{\text {oil }}=1457-4.1 T\right)$ agrees well with the measurements. 
sound speed measurements the tank was filled with the crude oil, covered in plastic wrap, insulated, and placed in a cold room at WHOI. The temperature was then decreased in the cold room and a $100 \mu$ s linear frequency-modulated signal from 250 to $750 \mathrm{kHz}$ was transmitted and recorded every $10 \mathrm{~s}$. The transducers were driven by the laboratory measurement system described in Bassett et al. (2014); Fig. 1. A thermistor in the oil, driven by an Arduino Uno, averaged 75 temperature measurements and recorded a single data point every $5 \mathrm{~min}$. The sound speed is determined by

$$
c=\frac{l_{o}}{t}
$$

where $l_{o}$ is the distance between the transducers and $t$ is the time delay of the first arrival calculated applying pulse compression techniques to the received signal (Sec. II D 1). Both the transmitted and received signals were sampled at $10 \mathrm{MHz}$. The uncertainty in the sound speed based on the direct path arrival time, $\sigma_{c}$, is described by

$$
\sigma_{c}=\sqrt{\left(\frac{1}{t} \sigma_{l_{o}}\right)^{2}+\left(\frac{-l_{o}}{t^{2}} \sigma_{t}\right)^{2}},
$$

where $\sigma_{l_{o}}$ is the uncertainty in the measured distance between the transducers, and $\sigma_{t}$ is the uncertainty in the measured time of arrival of the pulses.

The measured distance between the transducers at $23{ }^{\circ} \mathrm{C}$ was $27.4 \pm 0.1 \mathrm{~cm}$. For comparison, the tank was filled with fresh water from another tank where a Star-oddi (Skeidaras 12, 210 Gardabaer, Iceland) Starmon mini was used to measure the temperature $\left(20.56 \pm 0.02{ }^{\circ} \mathrm{C}\right)$. The sound speed of the fresh water was calculated to be $1484.1 \pm 0.1 \mathrm{~m} / \mathrm{s}$ (Del Grosso and Mader, 1972). The same signals used to calculate the oil sound speed were used to estimate the uncertainty in the temporal resolution of $E_{\mathrm{CP}}$ and to compare the measured and acoustical inferred distance between the transducers. A total of 50 pings were averaged prior to calculating $E_{\mathrm{CP}}$. Rearranging Eq. (3) to solve for $l_{o}$ and applying the sound speed of the water and $t$ from the peak in $E_{\mathrm{CP}}$, the calculated distance between the transducers was $27.5 \pm 0.1 \mathrm{~cm}$, a value indistinguishable from the manual measurement. The temporal uncertainty, $\sigma_{t}=0.5 \mu \mathrm{s}$, was determined as the length of time over which $E_{\mathrm{CP}}$ exceeded $95 \%$ of its peak value. Following Eq. (4) the calculated uncertainty was $5.9 \mathrm{~m} / \mathrm{s}$.

With the experimental apparatus experiencing a large temperature range, thermal expansion could affect sound speed measurements. Linear thermal expansion is described by

$$
d l=l_{o} \alpha\left(T_{f}-T_{i}\right)
$$

where $d l$ is the change in length, $l_{o}$ is the initial length, $T_{f}$ is the final temperature, and $T_{i}$ is the initial temperature. Using the coefficient of linear thermal expansion for Delrin ${ }^{\circledR},{ }^{1}$ $\alpha=12 \times 10^{-5} 1 /{ }^{\circ} \mathrm{C}$, the change in distance between the transducers from $20{ }^{\circ} \mathrm{C}$ to $-10{ }^{\circ} \mathrm{C}$ is approximately $-3.6 \mathrm{~mm}$. This $3.6 \mathrm{~mm}$ contraction is larger than the uncertainty in the range based on the measurements made at room temperature. Therefore, the thermal expansion term is included in the analysis and the equation for sound speed becomes

$$
c=\frac{l_{o}\left(1+\alpha\left[T_{f}-T_{i}\right]\right)}{t} .
$$

\section{F. Supporting measurements}

The properties of the water were determined throughout the experiment using a SonTek CastAway ${ }^{\circledR}$ CTD sensor. The water sound speeds were calculated according to Chen and Millero (1977). To independently monitor ice growth and the temperature of the ice, two thermistor strings were deployed in the tank prior to freezing. Each thermistor string had independent sensors spaced at $10 \mathrm{~cm}$ intervals from the water-air interface to the bottom of the tank. CTD casts and thermistor string temperature profiles were obtained on a regular basis throughout the experiment.

Ice cores taken at different stages of the experiment were analyzed to determine the ice thickness, investigate the microstructure of the ice, measure the salinity of the ice, and to observe the impact of the oil injections on the ice, with a particular focus on the skeletal layer. At the time of each injection $7.5 \mathrm{~cm}$ diameter ice cores were drilled outside of the oil containment curtains. Ice cores used to investigate the impact of the oil injections were drilled in the small hoops soon after the injections while ice cores in the large hoops were drilled at the end of the experiment. In all cases, care was taken to avoid damaging the fragile skeletal layer and to obtain the entire ice core. For cores with encapsulated oil, this included two crystallographically disconnected subcores separated by the oil layer. During all coring periods, multiple ice cores were obtained. Two cores were used to determine the physical state of the ice (e.g., salinity, density, thickness, and crystallography) while a separate core was used for ice microstructure observations. All cores were digitally imaged immediately after drilling.

Ice microstructure was investigated using a SkyScan1173 benchtop, research-grade micro computed tomography (micro-CT) scanner that was modified to work in a $-10{ }^{\circ} \mathrm{C}$ cold room. Ice cores were sectioned so that the bottom $10 \mathrm{~cm}$ of the core was first cut, then placed top-side down in a container to allow brine to drain out of the sample without damaging the fragile skeletal layer. The bottom of the core was taken to the micro-CT facility for scans immediately after drilling. Remaining portions of the cores were bagged and scanned in $10 \mathrm{~cm}$ sections, typically within $24 \mathrm{~h}$. All ice cores were stored at colder temperatures, which likely resulted in some freezing of the brine channels. Most cores were scanned with a $65 \mu \mathrm{m}$ resolution although a subset of ice cores with encapsulated oil was scanned at $40 \mu \mathrm{m}$. The relevant results from the micro-CT scans include the thickness of the skeletal layer, which was defined as the portion of the ice sheet in contact with the water that contained space between dendrites; brine channel size and orientation; and the dimensions and spacing of dendrites. 


\section{A 1D NORMAL INCIDENCE ACOUSTIC BACKSCATTER MODEL FOR CRUDE OIL UNDER SEA ICE}

Backscatter observations from a crude oil layer under congelation ice prior to the encapsulation have shown that under controlled conditions the signal is consistent with 1D reflections from a three-layered medium (water, crude oil, and ice) with smooth interfaces (Bassett et al., 2015). The reflection coefficient as a function of frequency is described by

$$
\mathcal{R}(k)=\frac{\mathcal{R}_{\mathrm{w}, \text { oil }}+\mathcal{R}_{\text {oil }, \text { ice }} \mathrm{e}^{2 \mathrm{j} k h_{\text {oil }}}}{1+\mathcal{R}_{\mathrm{w}, \text { oil }} \mathcal{R}_{\text {oil, }, \text { ice }} \mathrm{e}^{2 \mathrm{j} k h_{\text {oil }}}},
$$

where $\mathcal{R}$ is the total reflection coefficient, $\mathcal{R}_{w, \text { oil }}$ is the reflection coefficient at the water-oil interface, $\mathcal{R}_{\text {oil,ice }}$ is the reflection coefficient at the oil-ice interface, $k$ is the vertical wavenumber in the oil, and $h_{\mathrm{oil}}$ is the thickness of the crude oil layer (Medwin and Clay, 1998). All of the important input parameters to this simple model were measured and/or constrained by the experiment and are described below.

\section{A. Water properties}

Given the reflection coefficients in Eq. (7), the acoustic properties of the different layers determine not only the amplitude but also the structure of the echoes. The temperatures and salinities observed throughout the experiment ranged from $-0.7{ }^{\circ} \mathrm{C}$ to $-2.4{ }^{\circ} \mathrm{C}$ and 26.8 to $37.4 \mathrm{PSU}$, respectively. These values correspond to densities of $1022-1031 \mathrm{~kg} / \mathrm{m}^{3}$ and sound speeds of $1435-1441 \mathrm{~m} / \mathrm{s}$. Given these ranges, the acoustic impedance of the water changed less than $2 \%$ throughout the experiment, so representative values $\left(\rho_{\mathrm{w}}=1024 \mathrm{~kg} / \mathrm{m}^{3}, c_{\mathrm{w}}\right.$ $=1437 \mathrm{~m} / \mathrm{s}$ ) are used along with the acoustic properties of the oil (described below) to calculate the reflection coefficient at the water-oil interface.

\section{B. Properties of the ice}

In Bassett et al. (2015) the lowest frequency analyzed was $200 \mathrm{kHz}$ and, due to the short wavelengths, $\mathcal{R}_{\text {oil,ice }}$ was assumed to be a function of only the mismatch in acoustic impedance between the oil and the bottom of the ice. In practice, sound speed and density gradients near the water-ice interface result in a frequency-dependent reflection coefficient that are important at lower frequencies $(f<100 \mathrm{kHz})$ (Garrison et al., 1991; Williams et al., 1992; Winebrenner, 1992; Mourad and Williams, 1993). The reflection coefficient is calculated by assuming a smooth interface and applying a modified version of the hyperbolic tangent-based sound speed profile described in Winebrenner [1992, Eq. (40)] where the water properties have been replaced with oil. Here, the sound speed profile is described by

$$
c_{\text {ice }}(z)= \begin{cases}\left(2 c_{a}-c_{1}\right)+\left(c_{1}-c_{a}\right)\left[1+\tanh \left(\delta_{o} z\right)\right], & z>0 \\ c_{\text {oil }}, & z<0,\end{cases}
$$

where $c_{\text {oil }}$ is the sound speed of the oil, $c_{1}(3800 \mathrm{~m} / \mathrm{s})$ is the bulk sound speed of the ice, $c_{a}(1700 \mathrm{~m} / \mathrm{s})$ is the sound speed of the ice at the oil-ice interface, and $\delta_{o}=150$. Analysis of ice cores and micro-CT scans obtained prior to oil injection revealed skeletal layers up to $2 \mathrm{~cm}( \pm 0.5 \mathrm{~cm})$ thick. During the growth and encapsulation stages of the experiment dendrite thicknesses were $0.3-0.6 \mathrm{~mm}$ and dendrite spacing ranged from 0.2 to $0.6 \mathrm{~mm}$ with no clear patterns emerging over the period presented here. This parameterization of the sound speed profile reaches the bulk sound speed of the ice at approximately $2 \mathrm{~cm}$ rather than the roughly $5 \mathrm{~cm}$ used by Garrison et al. (1991) and Winebrenner (1992). Typical bulk salinity measurements for the cores ranged from 5 to 9 parts per thousand throughout the experiment with maximum salinities near the water-ice interface. Thermistor chains frozen into the ice generally showed linear temperature profiles. Density measurements of the ice were typically around $900 \mathrm{~kg} / \mathrm{m}^{3}$. This is low for young and first-year ice, suggesting these densities may have been altered by the drainage of brine during the coring process. For the model, the density of the ice is assumed to be $920 \mathrm{~kg} / \mathrm{m}^{3}$, a value consistent with in situ observations of first-year sea ice below the waterline (Timco and Frederking, 1996). The bulk salinity and temperature profiles are consistent with ice properties obtained in previous in situ acoustics experiments (e.g., Garrison et al., 1991). The relative change in density between the water and ice is small $(\leq 10 \%)$ compared to the change in sound speed $(\geq 250 \%)$ so the impact of assuming a constant density within the ice is limited (Winebrenner, 1992).

\section{Acoustic properties of crude oil}

The oil densities measured at $0 \%$ evaporation by volume were 889 and $874 \mathrm{~kg} / \mathrm{m}^{3}$ at $0{ }^{\circ} \mathrm{C}$ and $20^{\circ} \mathrm{C}$, respectively. Figure 4(b) shows the results of the oil sound speed as a function of temperature using Eqs. (4) and (6). The measured sound speeds ranged from approximately $1500 \mathrm{~m} / \mathrm{s}$ at $-10{ }^{\circ} \mathrm{C}$ to $1365 \mathrm{~m} / \mathrm{s}$ at $20^{\circ} \mathrm{C}$. A linear fit to the data, where $c=1457-4.1 T$, shown in Fig. 4, agrees well with the measurements. A sound speed of $1457 \mathrm{~m} / \mathrm{s}$ and a density of $889 \mathrm{~kg} / \mathrm{m}^{3}$ (oil at $0{ }^{\circ} \mathrm{C}$ ) are applied to calculate the reflection coefficients from the water-oil and oil-ice interfaces. The temperature of the oil at the time of the injection was approximately $0{ }^{\circ} \mathrm{C}$ and while it is expected that the oil immediately begins to lose energy to the surrounding ice and water, the initial assumption of $0{ }^{\circ} \mathrm{C}$ is appropriate because (1) reasonable bounds on the oil temperature result in only small changes to the acoustic properties $(<2 \%)$, and (2) encapsulation begins once the oil temperature is sufficiently low to allow water below the oil layer to freeze, which had not yet occurred for the data and models comparisons presented here.

\section{RESULTS}

\section{A. Normal incidence backscatter from sea ice}

The observed backscatter from the water-ice and oil-ice interfaces is frequency-dependent. Figure 5 shows normal incidence $E_{\mathrm{CP}}$ and $R_{P}$ derived from 225 pings (with no oil) obtained with the cart between two hoops. The envelopes 

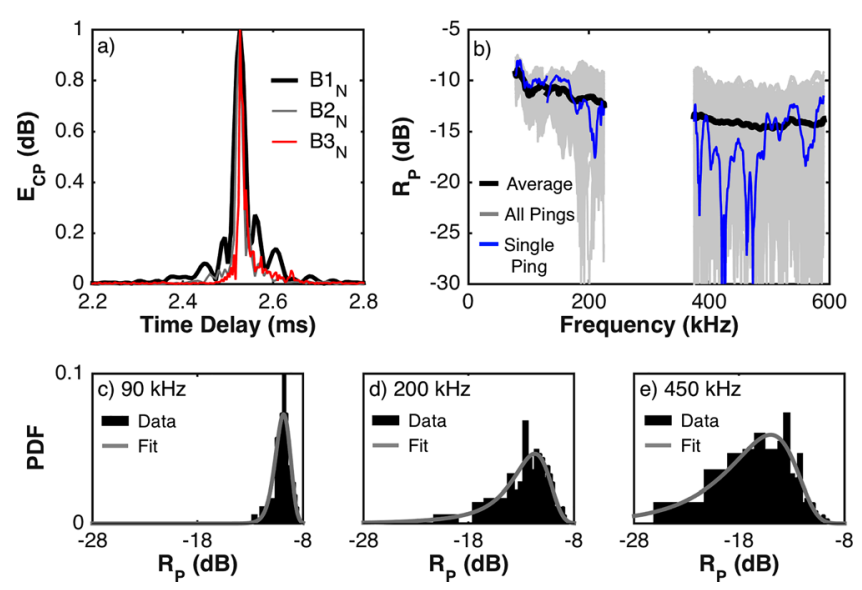

FIG. 5. (Color online) (a) Normalized $E_{\mathrm{CP}}$ for the normal incidence channels for a representative ping under ice (no oil). (b) The mean backscatter spectrum for 225 pings under ice, a representative spectrum from a single ping, and the envelope showing the spectra for the 225 pings contributing to the average. (c)-(e) PDFs and Rician fits to the PDFs for select frequencies from $R_{P}$ for the 225 pings in (a). At $90 \mathrm{kHz}$ the distribution is Gaussian-like $(\gamma=6.0)$ while the 200 and $450 \mathrm{kHz}$ distributions are increasingly Rayleighlike $(\gamma=2.2$ and 0.3 , respectively).

from $\mathrm{B} 1_{\mathrm{N}}$ are relatively stable. That is, there is only a small amount of variability in amplitude $(<20 \%)$, the envelopes contain a single peak associated with the water-ice interface, and the inferred range to the interface is constant from pingto-ping. At higher frequencies the amplitudes of the peaks in $E_{\mathrm{CP}}$ are lower but more variable. This variability is attributed to the small-scale structure of the skeletal layer of ice, volume inhomogeneities (e.g., brine channels), and to largerscale undulations on the bottom of the ice.

The $R_{P}$ spectrum [Fig. 5(b)] shows a decrease in the mean amplitude from $-9 \mathrm{~dB}(\mathcal{R}=0.13)$ at $75 \mathrm{kHz}$ to roughly $-15 \mathrm{~dB}(\mathcal{R}=0.03)$ across the $390-590 \mathrm{kHz}$ band. The gray spectra, one for each of the 225 pings, show that the variability in the backscatter spectra is small at the lowest frequencies $( \pm 2 \mathrm{~dB})$ but significant $(+5 /-15 \mathrm{~dB})$ at the high frequencies for the aforementioned reasons. At low frequencies these observations agree well with a reflection coefficient curve based on a hyperbolic tangent sound speed profile in the ice (Garrison et al., 1991; Winebrenner, 1992), which allows short wavelengths to be more effectively transmitted across the water-ice interface. However, at high frequencies the observations diverge and are lower in amplitude than a smooth water-ice interface with the modeled sound speed profile alone would predict. PDFs at 90,200 , and $450 \mathrm{kHz}$ and their fits to a Rice distribution [Figs. 5(c)-5(e)] show the gradual shift from a Gaussian-like distribution at $90 \mathrm{kHz}$ to a Rayleigh-like distribution at $450 \mathrm{kHz}$. This transition in the distribution type, in addition to the variability noted in Fig. 5(a) at relatively high frequencies, suggests that, as discussed in Stanton et al. (1986), the roughness of the ice relative to the acoustic wavelength plays an important role in highfrequency $(f>150 \mathrm{kHz})$ scattering from the ice.

\section{B. Backscatter from crude oil under ice prior to encapsulation}

$E_{\mathrm{CP}}$ and $R_{P}$ for different oil thicknesses are shown in Figs. 6(a)-6(d) and 6(e)-6(h), respectively. The acoustically
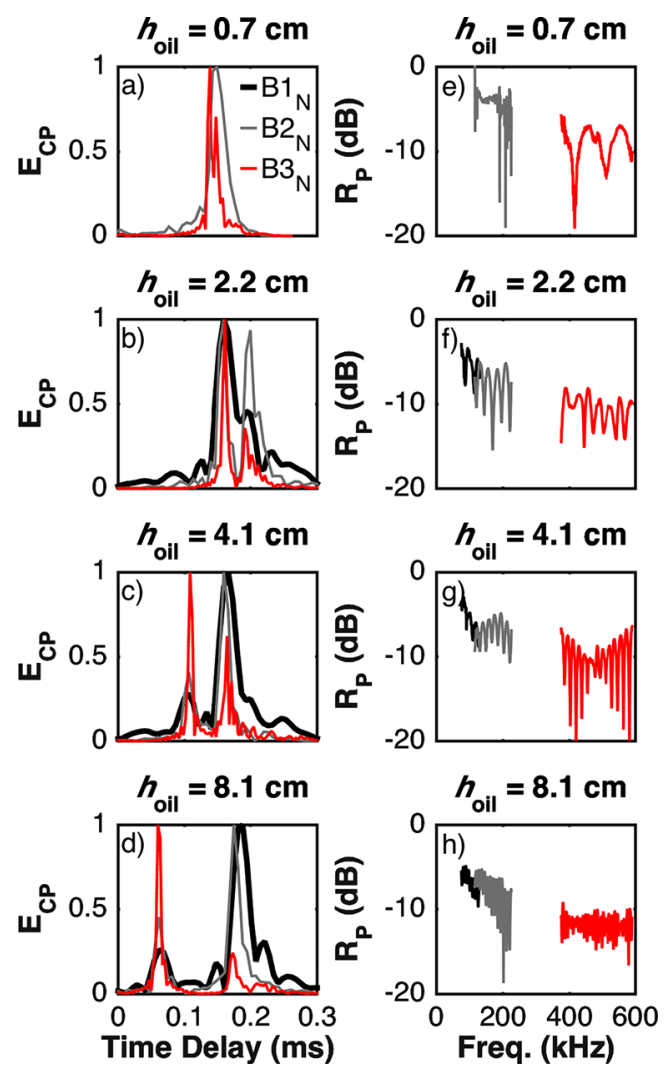

FIG. 6. (Color online) (a)-(d) Normalized $E_{\mathrm{CP}}$ for all three frequency bands and oil layers of different thicknesses. The $x$ axes for the $E_{\mathrm{CP}}$ figures are arbitrarily shifted to simplify comparisons between the signals because the range to the ice was different for each oil injection. Echoes from both the water-oil and oil-ice interfaces are seen in the $\mathrm{B} 3_{\mathrm{N}}$ for all oil thicknesses while the temporal resolution for $\mathrm{B} 2_{\mathrm{N}}$ is less than the thickness of the oil layer in (a) so only a single peak appears in $E_{\mathrm{CP}}$. (e)-(h) The backscatter spectra associated with $E_{\mathrm{CP}}$ in (a)-(d). The null patterns in the backscatter spectra are consistent with the presence of an oil layer with the null spacing being inversely proportional to the thickness of the oil layer.

inferred $h_{\text {oil }}$ values (assuming $c_{\text {oil }}=1457 \mathrm{~m} / \mathrm{s}$ ) shown in these figures range from 0.7 to $8.1 \mathrm{~cm}$. The impact of the effective bandwidth for the different transducers is evident in $E_{\mathrm{CP}}$. For the $\mathrm{B} 3_{\mathrm{N}}$ echoes, which also have the largest bandwidth, the envelopes show distinct arrivals from the water-oil and oilice interfaces in all four cases. Furthermore, the amplitude of the echoes associated with the water-oil interface are larger than those associated with the oil-ice interface. For B2 $2_{\mathrm{N}}$ echoes both interfaces are identifiable only when the oil thickness exceeds $0.8 \mathrm{~cm}$. For thinner oil layers only a single echo is present because the bandwidth and associated temporal resolution are insufficient to resolve both interfaces. For $\mathrm{B} 1_{\mathrm{N}}$ the bandwidth limits the identification of echoes from both interfaces to oil layers thicker than $1.6 \mathrm{~cm}$. In contrast to the higher-frequency channels, in some cases the echo from the water-oil interface is larger in amplitude while in other cases the echo from the oil-ice interface is larger. The precise physical mechanism for these differences cannot be ascertained with the available measurements.

As predicted by Eq. (7), the backscatter spectra [Figs. 6(e)-6(h)] show a pattern of peaks and nulls that are consistent with scattering from multiple interfaces. The spacing of the nulls, as expected based on the model, decreases as $h_{\text {oil }}$ increases. Although the relative amplitudes of $E_{\mathrm{CP}}$ for the 
water-oil and oil-ice interfaces vary for the different $h_{\text {oil }}$ values, the spectra show that the peak amplitudes of the spectra in the different frequency bands are comparable for each of the oil thicknesses. The depth of the nulls, however, is sensitive to the relative amplitudes of the peaks in $E_{\mathrm{CP}}$ associated with the interfaces (the nulls are deepest when the amplitude of the echoes are comparable). In Fig. 6(b) $\left(h_{\text {oil }}=0.7 \mathrm{~cm}\right)$, the spectrum from 120 to $220 \mathrm{kHz}$ does not show the peaks and nulls consistent with the oil layers because the bandwidth does not allow the resolution of both interfaces; however, the amplitude of the spectrum is greater than the amplitudes typically observed from ice scattering alone, suggesting that even thin oil layers may be resolvable due to changes in the echo amplitudes.

\section{Normal versus oblique incidence backscatter}

$E_{\mathrm{CP}}$ and $R_{P}$ for normal incidence data are compared to co-located and co-temporal $20^{\circ}$ incidence angle measurements in Fig. 7. Unlike the normal incidence observations, the oblique backscatter results do not include well-defined echoes from interfaces during transects under the oil injections. The echoes from the water-oil and oil-ice interfaces do, however, appear more variable than echoes from the waterice interface and suggest that volume scattering from inhomogeneities in the oil and ice and interface roughness may be important at oblique angles. Comparisons between the normal and oblique incidence backscatter spectra with and without an oil layer are compared in Figs. 7(c) and 7(d). Under both ice and oil, $\mathrm{B} 1_{\mathrm{N}}$ and $\mathrm{B} 2_{\mathrm{N}}$ spectra are flat or decrease with frequency due to sound speed structure of the ice and interfaces. At these same frequencies the trend in the oblique spectra is the opposite; the amplitudes increase with frequency. This trend is attributed to a relative decrease in the acoustic roughness of the interface at lower frequencies. $\mathrm{B} 3_{\mathrm{N}}$ and $\mathrm{B} 3_{\mathrm{O}}$ spectra are, on average, of comparable amplitude under ice, but in the presence of oil the normal incidence
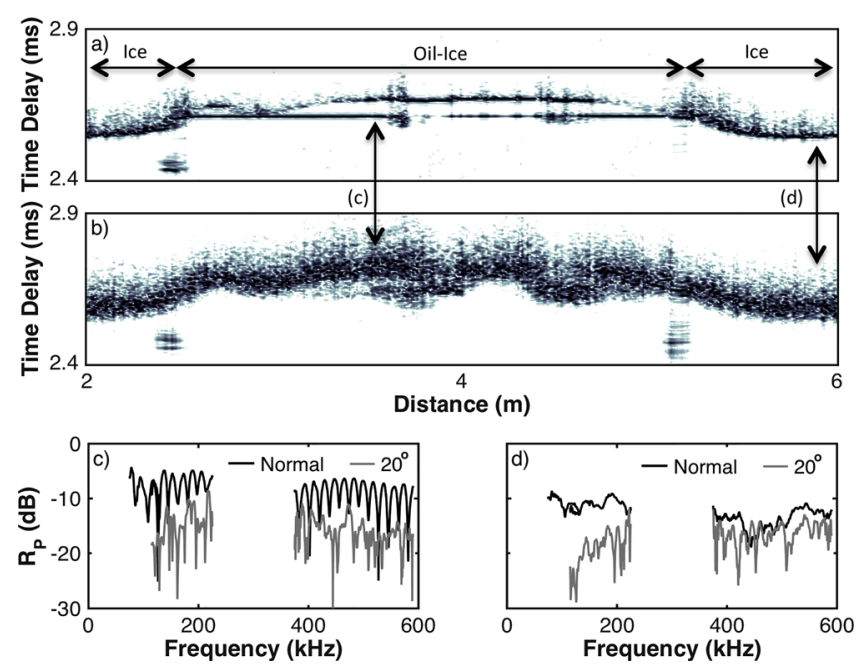

FIG. 7. (Color online) Transect under the Hoop 4 injection. (a) Normalized $E_{\mathrm{CP}}$ from $\mathrm{B} 3_{\mathrm{N}}$. (b) Normalized $E_{\mathrm{CP}}$ from $\mathrm{B} 3_{\mathrm{O}}$. The locations of the individual pings for panels (c) and (d) are highlighted. (c) Spectra for the normal and $20^{\circ}$ incidence angles from the oil-ice. (d) Spectra for the normal and $20^{\circ}$ incidence angles from the ice. echoes are higher in amplitude and well-structured in comparison to the oblique observations.

\section{Model-data comparisons}

The modeled normal incidence, frequency-dependent reflection coefficients for the different interfaces, in addition to a comparison between the observed and modeled total reflection coefficients for two oil thicknesses (0.7 and $4.1 \mathrm{~cm}$ ), are shown in Fig. 8. Model results in Fig. 8(b) are based on an independent fit to the peaks/nulls in $\mathrm{B} 3_{\mathrm{N}}$ because no null structure is resolved with the lower-frequency channels. Each spectrum in Fig. 8(c) is fit independently, which is important because the null spacing is not highly sensitive to the oil thickness but the location of the nulls is. In general, the difference between the minimum and maximum oil thicknesses inferred from the fits is less than $10 \%$. In addition to good agreement between the modeled structure and the observations, the increasing reflection coefficient at low frequencies is observed in both the data and the model and supports the use of the sound speed gradient in the ice at these frequencies.

Figures 9(a) and 9(b) include $E_{\mathrm{CP}}$ and $R_{P}$ observations as the cart moved from ice, under the oil, and back to ice. As the cart moves under the hoop the unique interfaces both become identifiable in $E_{\mathrm{CP}}$ [Fig. 9(a)] before the layer becomes thinner as the cart moves back to the ice on the other side. Likewise, in $R_{P}$ [Fig. 9(b)] the signals associated with the oil layer are quite clear. While under the oil layer the peak/null patterns are present in the spectra and the
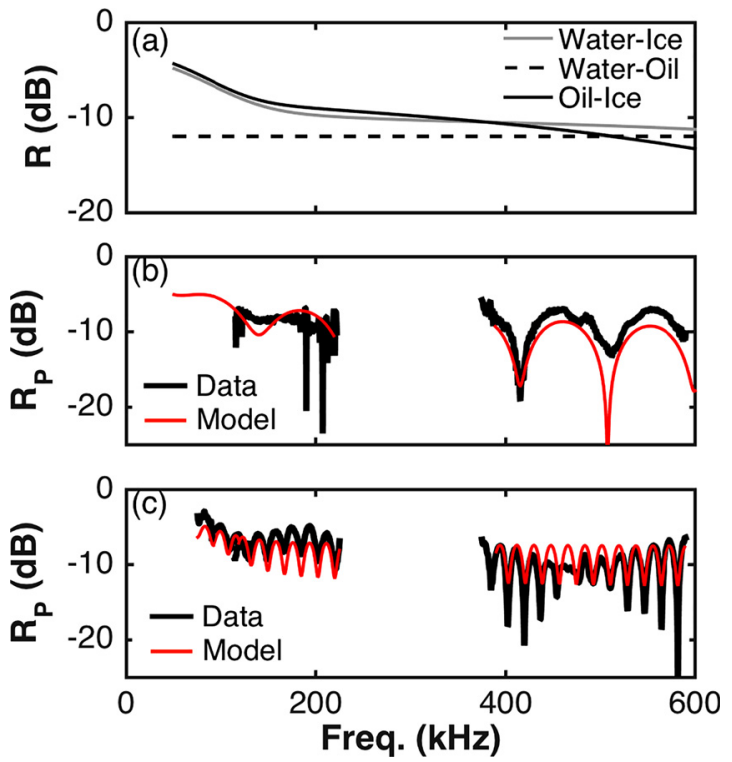

FIG. 8. (Color online) (a) Modeled reflection coefficients for the different interfaces in isolation. The reflection coefficient at the water-oil interface is frequency-independent because the water and oil layers are homogeneous whereas the reflection coefficients at the water-ice and oil-ice interfaces are frequency-dependent because of the sound speed gradient in the ice. The reflection coefficient of the water-oil interface is dominated by the density contrast $\left(c_{\mathrm{w}} / c_{\mathrm{oil}}=0.99\right.$ whereas $\left.\rho_{\mathrm{w}} / \rho_{\text {oil }}=1.15\right)$. (b) A comparison between the model and data for a $0.7 \mathrm{~cm}$ inferred oil thickness. The null near $150 \mathrm{kHz}$ is not resolved because the temporal resolution of $\mathrm{B} 2_{\mathrm{N}}$ was insufficient to resolve both interfaces. (c) A comparison between the model and data for a $4.1 \mathrm{~cm}$ inferred oil thickness. 
gradual shifts in the null spacing as the thickness of the oil layer changes can be followed visually. Using $E_{\mathrm{CP}}$ and $R_{P}$ the thickness of the oil layer is inferred and plotted versus the under-ice locations in Fig. 9(c) according to descriptions in Secs. II D 1 and II D 2. These two approaches to inferring $h_{\text {oil }}$ from normal incidence data agree well despite their simplicity, which suggests that an automated approach to identification of oil layers under ice is feasible.

\section{E. Normal incidence backscatter from crude oil encapsulated in ice}

The results in Secs. IV A-IVD demonstrate that the presence an oil layer under ice is detectable prior to encapsulation in both the frequency and temporal domains. Following the oil injection the vertical temperature gradient across the ice results in continual cooling of the oil layer until the temperature is sufficiently low to permit further ice growth. Figure 10(a) shows a time series of $E_{\mathrm{CP}}$ using the normal incidence low-frequency transducer for $160 \mathrm{~h}$ following one of the oil injections. Based on these data, acoustically inferred encapsulation of the oil occurs approximately $75 \mathrm{~h}$ after the oil injection. While the presence of multiple echoes near the initial water-oil interface is a clear indication of encapsulation, the process can also be inferred by an increase in the apparent temporal "width" of the interface prior to being able to independently resolve both interfaces [e.g., compare envelopes at $60 \mathrm{~h}$ and approximately $115 \mathrm{~h}$ in Fig. 10(a)]. Due to the bandwidth of the low-frequency transducer, encapsulation was not evident in changes in $E_{\mathrm{CP}}$ until the inferred range to the bottom interface had changed by more than $2 \mathrm{~cm}$.
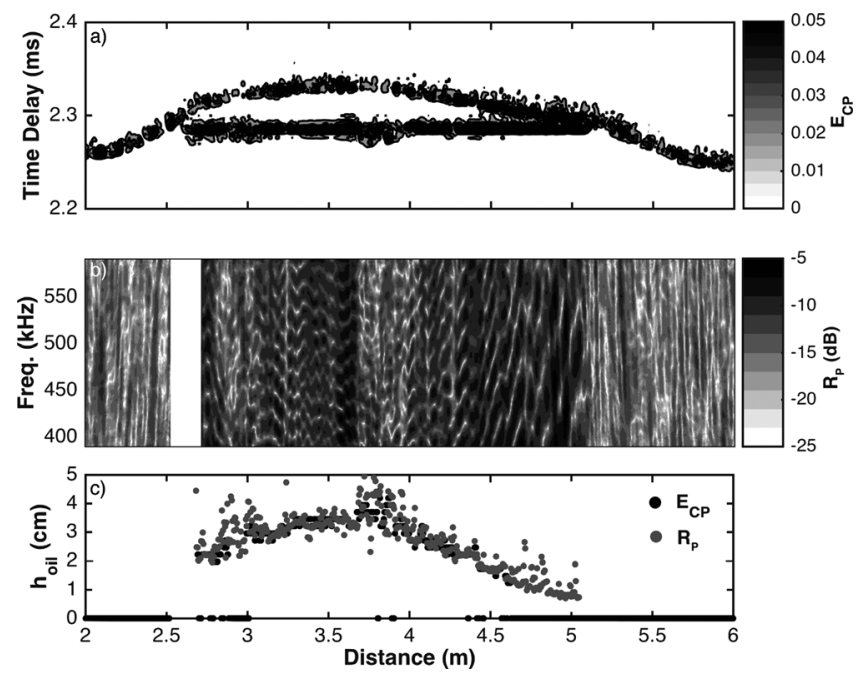

FIG. 9. Transect under the Hoop 5 injection. (a) Contours of $E_{\mathrm{CP}}$ from $\mathrm{B} 3_{\mathrm{N}}$ obtained during transect under an oil injection prior to encapsulation. The topography of the ice under which the oil is pooled is attributed to insulation placed on top of the ice in the hoops to retard growth, forcing the oil to pool in the center. Within the hoop the contours clearly show both the water-oil and oil-ice interfaces. (b) A spectrogram of the data in (a). When the cart is below the oil layer the spectrogram shows clear peak/null patterns consistent with the model. Gradual shifts in the null spacing as the thickness of the oil layer changes can be followed visually. The blank space between 2.5 and $2.7 \mathrm{~m}$ is data that was removed because of interference from the oil containment curtain. (c) Acoustically inferred oil layer thicknesses derived from both the temporal- and frequency-domain results.
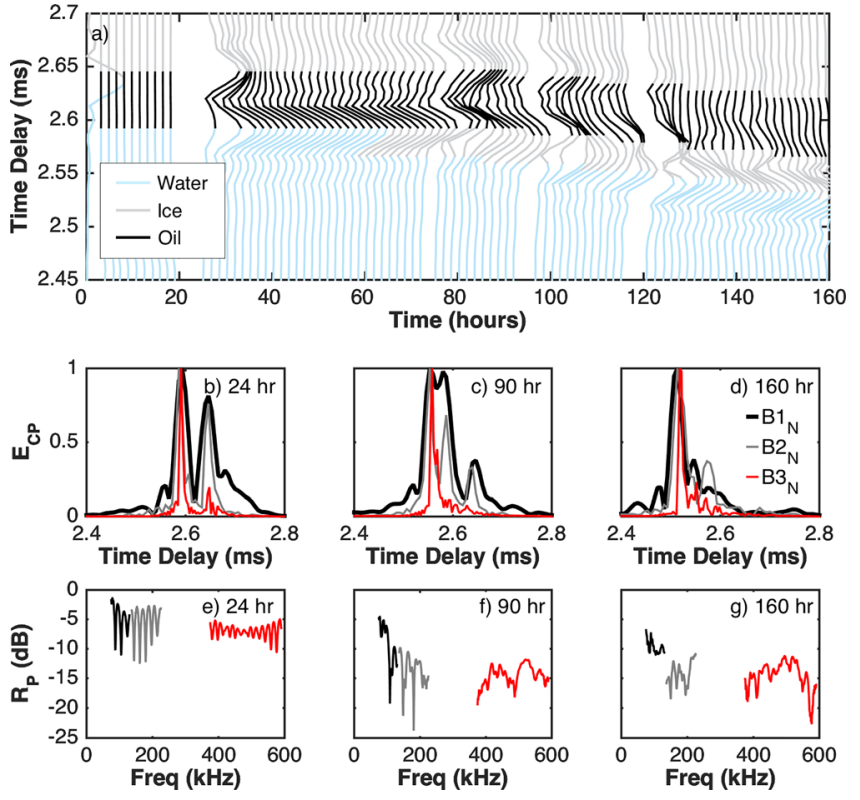

FIG. 10. (Color online) (a) A time series of $E_{\mathrm{CP}}$ from $\mathrm{B} 1_{\mathrm{N}}$ from prior to an oil injection until more than $6 \mathrm{~cm}$ of encapsulation (acoustically inferred) has occurred. The colors show the interpretation of the data. (b)-(d) $E_{\mathrm{CP}}$ from $\mathrm{B} 1_{\mathrm{N}}, \mathrm{B} 2_{\mathrm{N}}$, and $\mathrm{B} 3_{\mathrm{N}}$. At $24 \mathrm{~h}$ (b) encapsulation had not occurred. At $90 \mathrm{~h} \mathrm{(c)} \mathrm{and} 160 \mathrm{~h} \mathrm{(d),} 2.9$ and $5.3 \mathrm{~cm}$ of ice had grown below the oil layer. (e)-(g) $R_{P}$ at 24,90 , and $160 \mathrm{~h}$. Following encapsulation the amplitude of $R_{P}$ decreases by more than $5 \mathrm{~dB}$ and the structure of the spectra becomes increasingly complex, indicating the presence of an additional interface.

Figures $10(\mathrm{~b})-10(\mathrm{~g})$ include examples of $E_{\mathrm{CP}}$ and $R_{P}$ at three times following the oil injection. At $24 \mathrm{~h}$, encapsulation had not occurred while at 90 and $160 \mathrm{~h}$ the amount of inferred encapsulation was 2.9 and $5.3 \mathrm{~cm}$, respectively. In Fig. 10(c) $(90 \mathrm{~h})$ there are clear echoes from three interfaces (water-ice, ice-oil, and oil-ice) for the $\mathrm{B} 1_{\mathrm{N}}$ and $\mathrm{B} 2_{\mathrm{N}}$ channels. At $160 \mathrm{~h}$ [Fig. 10(d)] the echoes are consistent with multiple interfaces, which, as shown in Fig. 5(a), do not typically occur from ice only. However, the echoes are not as well-defined as at $90 \mathrm{~h}$. Nulls and peaks remain present in $R_{P}$ following encapsulation but structure of the spectra is more complex. With time following oil encapsulation the spectra become more consistent with scattering from ice alone. Here, the time-gates used are sufficiently long to include echoes from all interfaces with the exception of the ice-air interface. The use of shorter time gates that result in the exclusion of a given interface would decrease the complexity of the interference patterns from the multiple interfaces.

\section{F. Ice cores}

A backlit slab cut from the ice above an oil injection, an ice core following oil encapsulation, and micro-CT scans of skeletal layers are shown in Fig. 11. The presence of oil within the brine channels is clearly evident although the total oil entrainment is limited to a small portion of the volume of the slab. As shown in Fig. 11(b), the skeletal layer of the ice remains intact despite being in contact with the oil layer. All slabs and ice cores [Fig. 11(c)] confirm that for encapsulated oil the ice layers were crystallographically disconnected and that no oil was present in the ice layer growing beneath the oil. Micro-CT scan results, including ice outside of a hoop 


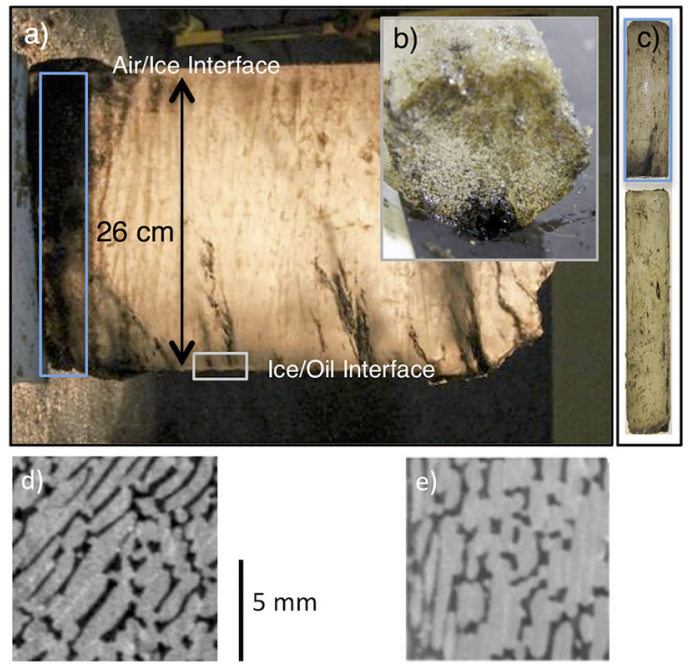

FIG. 11. (Color online) (a) A wedge-shaped slab of ice cut from the ice sheet above an oil injection shows the percolation of oil into the brine channels above the oil-ice interface. Although the presence of oil within the brine channels is evident, the total amount of oil within the ice by volume is small. The rectangular insets highlight the portions of the slab that are shown in greater detail by (b) and (c). (b) The complex skeletal layer above the oil-ice interface appears intact despite being in contact with the oil. (c) An ice core including two separate portions of ice. The top of the core extended from the air-ice interface to the oil-ice interface and the bottom portion of the core extended from the oil-ice interface to the ice-water interface. The top portion shows oil percolation into a brine channel above the oil-ice interface. The oil visible on the lower core is superficial and a result of the coring process. (d) Micro-CT scan of the skeletal layer outside of a hoop (no oil). (e) Micro-CT scan of the skeletal layer within a hoop (exposed to oil). Scans (d) and (e) suggest that any changes to the skeletal layer resulting from exposure to the oil were not obvious.

[Fig. 11(d)] and ice from above an encapsulated oil layer [Fig. 11(e)], had similar dendrite geometries and skeletal layer thicknesses, further suggesting the oil had a limited impact on the skeletal layer. It is entirely possible that if the oil was injected at a higher temperature (in this case the oil temperature at the time of injection was approximately $0{ }^{\circ} \mathrm{C}$ ) that changes to the fragile skeletal layer would be more evident.

\section{DISCUSSION}

Results from this study demonstrate that under controlled laboratory conditions high-frequency broadband acoustic backscatter techniques can be used to detect crude oil spills both under and encapsulated in congelation ice. While lower frequencies penetrate further into the ice and scatter less from small-scale inhomogeneities, the useful bandwidth of lowerfrequency transducers is generally smaller, resulting in a coarser temporal resolution. Furthermore, the reflection coefficient of ice increases rapidly at low frequencies so a smaller proportion of the acoustic energy is transmitted through the water-ice interface (Garrison et al., 1991) where it is available to scatter from an encapsulated oil layer. The nominal center frequencies $(100,160$, and $500 \mathrm{kHz})$ of the transducers used in this experiment were motivated by previously published data about backscatter from sea ice (Stanton et al., 1986) and crude oil under sea ice (Bassett et al., 2014, 2015); the hypothesis being that these transducers and signals would strike an appropriate balance between the desired temporal resolution and the complexity of the echoes.

Observations of backscatter during spatial sampling under the ice outside of the oil containment curtains agree well with previous studies. At frequencies less than $150 \mathrm{kHz}$ the amplitudes of the backscatter spectra are consistent with a reflection coefficient curve that is dominated by the sound speed profile of ice (Garrison et al., 1991; Winebrenner, 1992). At higher frequencies the backscatter spectra are highly variable suggesting that the roughness of the ice plays an important role in the acoustic scattering as suggested by Stanton et al. (1986). Once oil is injected under the oil there is a significant (order $5 \mathrm{~dB}$ ) increase in the amplitude of the normal incidence backscatter spectra across all of the frequencies in this study. These increases in the amplitude of the echoes occur along with the ability to resolve echoes associated with both the water-oil and oil-ice interfaces when the temporal resolution permits. For all frequencies used in this experiment there is good agreement between the 1D normal incidence backscatter model based on the reflection coefficients calculated using the acoustic properties of the layers assuming smooth interfaces. In comparison to the normal incidence observations, the oblique data are difficult to interpret and are more spatially variable. An improved understanding of non-normal incidence backscatter would significantly improve the effectiveness of acoustic backscatter techniques for this application and should be the focus of future work.

Although not a significant source of uncertainty in this particular experiment due to the short ranges, the range dependence of backscatter from oil and ice would be required to quantify echo amplitudes in situ. Similarly, it was not possible to consider the impact of the acoustic footprint on the interpretation of the echoes. At larger ranges these terms could be important for two reasons. First, the spatial sampling under the injections (Fig. 9) suggests variability in oil thickness and interface roughness on sub-meter scales. Second, a natural ice sheet is expected to have more topographic variability, which could result in more irregular oil depths over relatively small spatial scales. Given that these uncertainties are critical to the interpretation of the data both topics should be the focus of further studies.

The simple 1D model captures the majority of features in the data, including the amplitudes and structure of the backscatter from the water-oil and oil-ice interfaces. However, the observations suggest that neither of the interfaces is acoustically smooth at all frequencies used in the study, which cannot be explained by such a simple model. For example, the spectra in Fig. 6(g) include additional oscillations occurring over changes in frequency that are much greater than the peak/null patterns associated with the thickness of the oil layer that may be attributed to small-scale interface roughness. This is consistent with the spatial observations and acoustical inferred oil thicknesses shown in Fig. 9 that suggest both a "rough" interface based on changes in $E_{\mathrm{CP}}$ at normal incidence and oil thicknesses that vary over distances comparable to the transducer footprints.

The mismatch between the acoustic impedances of the different layers is the basis of the model in this study and the 
properties of the oil are central to the success of the model. Using this model it is possible to show that changes in the acoustic properties of the oil can have significant implications for the detectability of an oil layer under ice. The density and sound speed are inversely related to the temperature (Batzle and Wang, 1992). To demonstrate the impact of the oil properties on the scattering, the acoustic properties of crude oil with API gravities from $20^{\circ}-40^{\circ}$ are calculated according to Eqs. (19) and (20) of Batzle and Wang (1992) at temperatures from $-15{ }^{\circ} \mathrm{C}$ to $5{ }^{\circ} \mathrm{C}$. These properties are used to calculate the dependence of $\mathcal{R}_{\mathrm{w}, \text { oil }}$ on temperature and API gravity [Fig. 12(a)], $\mathcal{R}_{\text {oil,ice }}$ as a function of frequency, and API gravity at $0{ }^{\circ} \mathrm{C}$ [Fig. 12(b)], and the total reflection coefficient given the API gravity at $0{ }^{\circ} \mathrm{C}$ [Fig. 12(c)]. The results show complex relationships between the temperature, API gravity, and frequency that are driven by the relative contributions of density and sound speed to the acoustic impedance and how rapidly these properties vary with temperature $\left(\partial c_{\text {oil }} / \partial T>\partial \rho_{\text {oil }} / \partial T\right)$. An API gravity greater than used in this experiment results in higher reflection coefficients at the same temperature due the decreases in density and sound speed with API gravity. For heavier oils this is not the case. In fact, for certain temperatures and API gravity combinations the acoustic impedance of the oil can match that of water [Fig. 12(a)]. When this occurs, assuming the oil layer is homogeneous, the reflection from the water-oil interface goes to zero and the total reflection coefficient matches that of the water-ice interface alone. For example, at $0{ }^{\circ} \mathrm{C}$ an oil with an API gravity approximately $26^{\circ}$ does not exhibit any nulls over the modeled frequency range and the total reflection coefficient is similar to ice alone [Fig. 12(c)], which would complicate the task of identifying an oil layer under those conditions.
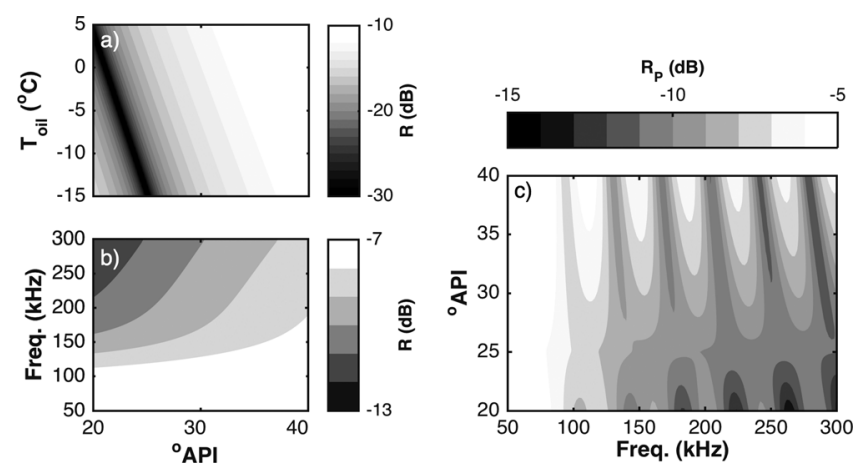

FIG. 12. Modeled reflection coefficients under different conditions assuming an oil layer thickness of $2 \mathrm{~cm}$. The API gravity for the experiments is $29.8^{\circ}$. (a) Modeled reflection coefficients from the water-oil interface as a function of temperature and API gravity. The minima are associated with API gravity/temperature combinations at which the acoustic impedance of oil most closely matches the acoustic impedance of the water. (b) The reflection coefficient at the oil-ice interface as a function of frequency and API gravity at $0{ }^{\circ} \mathrm{C}$. At $0{ }^{\circ} \mathrm{C}$ heavier oils (lower API) result in lower reflection coefficients. (c) Modeled total reflection coefficients versus API gravity and frequency at $0{ }^{\circ} \mathrm{C}$. When the combination of API gravity and temperature results in an acoustic impedance of oil similar to that of the seawater little energy is reflected back from the water-oil interface, the reflection coefficient at the oil-ice interface is similar to the water-ice interface, there are no nulls in the spectra, and the oil is difficult to detect. This is demonstrated by the model results between $25^{\circ}$ and $26^{\circ}$ API.
It was possible to observe the process of encapsulation. However, there was significant temporal variability observed in the echoes as the oil was encapsulated in the ice. Major structural changes in $E_{C P}$ are visible in the first $40 \mathrm{~h}$ of the encapsulation time series [Fig. 10(a)]. During this period the amplitude of $R_{P}$ remains roughly constant but the dominant scattering interface changes from the oil-ice interface to the water-oil interface for the $\mathrm{B} 1_{\mathrm{N}}$ channel. The echo from the water-oil interface is equal to or greater than the echo from the oil-ice interface throughout the same period for the $\mathrm{B} 3_{\mathrm{N}}$ channel. The physical mechanism responsible for these differences is unclear but could be related to a change in the interface roughness as the oil spreads and settles, ice crystal formation below the oil layer, the percolation of oil into the dendrites and brine channels of the ice, and changes to the acoustic properties of the oil as the temperature decreases.

As shown in Fig. 10, identification of the encapsulated oil layer became more difficult with time. This difficulty is attributed, in part, to the interference of bubbles, which began to buildup on the cart and rise to the surface. Bubble buildup on the bottles and bottom of the ice was first noticed approximately 1 week after the injection shown in Fig. 10. At that point the cart was extracted to remove the bubbles but the ice surface may have already been compromised. It is possible-perhaps likely-that echoes from oil encapsulated in sea ice remain identifiable over a broader range of ice thicknesses. The amplitudes of the transmitted signals were not changed at any point during the experiment and were sufficiently small to avoid saturating the received signals from a pressure-release surface at a range of $2.2 \mathrm{~m}$. Therefore, it is reasonable to expect that using higheramplitude transmit signals could overcome the scattering from the water-ice interface and attenuation in the ice and oil layers. Previous studies such as Stanton et al. (1986), which suggested that the attenuation within sea ice is greatest in the skeletal layer due to the high porosity and permeability, also support this hypothesis. This is further supported by observations that the absorption in the skeletal layer alone was between $2.5 \mathrm{~dB}$ at $37-92 \mathrm{kHz}$ (Wen, 1991) to $2-5 \mathrm{~dB} / \mathrm{cm}$ at $92 \mathrm{kHz}$ (Williams et al., 1992). Reported attenuation rates from sea ice, excluding the skeletal layer, are lower, ranging from $1 \mathrm{~dB} / \mathrm{m}$ at $10 \mathrm{kHz}$ to greater than $35 \mathrm{~dB} / \mathrm{m}$ at $500 \mathrm{kHz}$ (Langleben, 1969). These values suggest that a detecting strong echo from encapsulated oil at relatively low-frequencies (i.e., $f<120 \mathrm{kHz}$ ) should be possible at ice thicknesses greater than the $6 \mathrm{~cm}$ observed here given sufficient dynamic range. Encapsulated oil was not detected using the oblique backscatter channels. In addition to the aforementioned reasons, this may also be attributed to the relatively low signal-to-noise ratios in the $\mathrm{B} 1_{\mathrm{O}}$ and $\mathrm{B} 2_{\mathrm{O}}$ channels. The detection of encapsulated oil using both normal and non-normal incidence backscatter should be the focus of future studies.

The viscosity and surface tension of crude oils could further impact scattering by affecting the percolation of oil into the brine channels and changing the roughness of the water-oil interface. A higher viscosity oil is less likely to percolate up through the narrow dendrites and brine channels of the sea ice. It is currently unclear how significant the 
impact of percolation is on the backscatter. Although both the viscosity and surface tension affect the spreading/pooling of oil under ice, the impact of the oil properties is likely to be dominated by under-ice topography in natural settings (Fingas and Hollebone, 2003). The practical difficulties related to sampling the acoustic properties of the oil and ice layers during the experiment, determining changes to the small-scale ice structure due to the presence of the oil, and measuring the entrainment of the oil into the ice near the oil layer are all significant challenges that, if measured, could be used to further develop predictive models. Despite the unknowns and uncertainties, the agreement between observations and the model in addition to the clear differences between the backscatter from ice and oil under ice suggest that high-frequency broadband acoustic scattering techniques can be used to detect crude oil under sea ice.

\section{CONCLUSIONS}

Laboratory measurements of high-frequency broadband acoustic backscatter $(75-590 \mathrm{kHz})$ from crude oil layers of different thicknesses $(0.7-8.1 \mathrm{~cm})$ under and encapsulated in laboratory-grown sea ice have been performed. In comparison to previous studies, extensive environmental and acoustic property measurements were made to reduce uncertainties in model parameters and to aid in the interpretation of the data. The results show that high-frequency broadband acoustic scattering techniques can be used to identify and quantify layers of crude oil under laboratorygrown congelation ice. Bandwidth and frequency are important factors affecting the detectability of thin oil layers in temporal domain analysis. With the appropriate transducer parameters echoes from both the water-oil and oil-ice interfaces can be identified for oil layers thinner than $1 \mathrm{~cm}$ at normal incidence. A 1D model for the normal incidence, frequency-dependent backscatter with no free parameters captures both the observed amplitudes and spectral structure from the oil under ice. Measurements at a $20^{\circ}$ incidence angle are more complex than normal incidence observations and suggest volume scattering within the oil and ice and interface roughness are important. Normal incidence observations also demonstrate that it is possible to detect encapsulated oil layers. Despite remaining uncertainties (e.g., the range dependence of backscatter from oil and ice) this work suggests that high-frequency acoustic backscatter techniques could be a useful addition to an instrumentation package designed for under-ice oil spill detection.

\section{ACKNOWLEDGMENTS}

The authors would like to thank the technical staff in CRREL's Ice Engineering Division, especially Leonard Zabilansky, Ben Winn, Nate Lamie, and Jesse Stanley, for support throughout the project. Zoe Courville and Bruce Elder drilled and analyzed the ice cores. D. J. Tang and several reviewers provided valuable comments on the draft manuscript. In addition we thank Jessica Garron, Scott Pegau, and the Prince William Sound Science Center Oil Spill Recovery Institute. Funding for this research was provided by the International Oil and Gas Producers Arctic
Oil Spill Technology Joint Industry Programme under Contract No. 28-13-14. C.B. was supported by the WHOI Postdoctoral Scholar Program with funding from the United States Geological Survey. A.C.L. was supported in part by the Ocean Acoustics Program at the Office of Naval Research.

${ }^{1}$ Delrin ${ }^{\circledR}$ acetal resins, produced by DuPont ${ }^{\mathrm{TM}}$, have typical thermal expansion coefficients between 10 and $14 \times 10^{-5} 1 /{ }^{\circ} \mathrm{C}$ according to production data sheets [http://www2.dupont.com/Plastics/en_US/assets/downloads/ design/DELDGe.pdf (Last accessed January 29, 2016)].

ASTM Standard D4052-11 (2011). Standard Test Method for Density, Relative Density, and API Gravity of Liquids by Digital Density Meter (ATSM International, West Conshohocken, PA).

Bassett, C., Lavery, A. C., Maksym, T., and Wilkinson, J. P. (2014).

"Laboratory measurements of high-frequency, broadband acoustic scattering of growing sea ice and oil beneath sea ice," Proc. Mtg. Acoust. 21, 070008.

Bassett, C., Lavery, A. C., Maksym, T., and Wilkinson, J. P. (2015). "Laboratory measurements of high-frequency, acoustic broadband backscattering from sea ice and crude oil," J. Acoust. Soc. Am. 137(1), EL32-EL38.

Batzle, M., and Wang, Z. (1992). "Seismic properties of pore fluids," Geophys. 57(11), 1396-1408.

Cavalieri, D. J., and Parkinson, C. L. (2012). "Arctic sea ice variability and trends, 1979-2010," Cryosphere 6, 881-889.

Chen, C., and Millero, F. J. (1977). "Speed of sound in seawater at high pressures,” J. Acoust. Soc. Am. 62(5), 1129-1135.

Chu, D., and Stanton, T. K. (1998). "Application of pulse compression techniques to broadband acoustic scattering by live individual zooplankton," J. Acoust. Soc. Am. 104(1), 39-55.

Del Grosso, V. A., and Mader, C. W. (1972). "Speed of sound in pure water," J. Acoust. Soc. Am. 52(5), 1442-1446.

DiPerna, D. T., and Stanton, T. K. (1991). "Fresnel zone effects in the scattering of sound by cylinders of various lengths," J. Acoust. Soc. Am. 90(6), 3348-3355 (1991).

Fingas, M. F., and Hollebone, B. P. (2003). "Review of behaviour of oil in freezing environments," Mar. Poll. Bull. 47, 333-340.

Francois, R. E., and Garrison, G. R. (1982a). "Sound absorption based on ocean measurements: Part I: Pure water and magnesium sulfate contributions," J. Acoust. Soc. Am. 72(3), 896-907.

Francois, R. E., and Garrison, G. R. (1982b). "Sound absorption based on ocean measurements. Part II: Boric acid contribution and equation for total absorption," J. Acoust. Soc. Am. 72(6), 1879-1890.

Garrison, G. R., Francois, R. E., and Wen, T. (1991). "Acoustic reflections from arctic ice at 15-300 kHz,” J. Acoust. Soc. Am. 90(2), 973-984.

Gautier, D. L., Bird, K. J., Charpentier, R. R., Grantz, A., Houseknecht, D. W., Klett, T. R., Moore, T. E., Pitman, J. K., Schenk, C. J., Schuenemeyer, J. H., Sørensen, K., Tennyson, M. E., Valin, Z. C., and Wandrey, C. J. (2009). "Assessment of undiscovered oil and gas in the Arctic," Science 324(5931), 1175-1179.

Greene, G. D., Leinonen, P. J., and Mackay, D. (1977). "An exploratory study of the behaviour of crude oil spills under ice," Can. J. Chem. Eng. 55, 696-700.

Izumiyama, K., Uto, S., and Sakai, S. (2004). "Prediction of oil-ice sandwich formation,” Int. J. Offshore Polar Eng. 14(3), 169-175.

Karlsson, J., Petrich, C., and Eicken, H. (2011). "Oil entrainment and migration in laboratory-grown saltwater ice," in Proceedings of the 21st Conference on Port Ocean Engineering Under Arctic Conditions, POAC11-186, pp. 1-10.

Keevil, B., and Ramseier, R. (1975). "Behavior of oil spilled under floating ice," in International Oil Spill Conference Proceedings, Vol. 1975(1), pp. 497-501.

Kovacs, A., Morey, R. M., Cundy, D. F., and Decoff, G. (1981). "Pooling of oil under sea ice," in Proceedings of the 6th Conference on Port Ocean Engineering Under Arctic Conditions, POAC81, pp. 912-922.

Kunz, C., Murphy, C., Singh, H., Pontbriand, C., Sohn, R. A., Singh, S., Sato, T., Roman, C., Nakamura, K., Jakuba, M., Eustice, R., Camilli, R., and Bailey, J. (2009). "Toward extraplanetary under-ice exploration: Robotic steps in the Arctic," J. Field Robot. 26(4), 411-429. 
Langleben, M. P. (1969). "Attenuation of sound in sea ice, 10-500 kHz," J. Glaciol. 8(54), 399-406.

Lavery, A. C., Chu, D., and Moum, J. N. (2010). "Measurements of acoustic scattering from zooplankton and oceanic microstructure using a broadband echosounder,’ ICES J. Mar. Sci. 67, 379-394.

Lavery, A. C., and Ross, T. (2007). "Acoustic scattering from doublediffusive microstructure," J. Acoust. Soc. Am. 122(3), 1449-1462.

Lewis, E. (1976). Oil In Sea Ice (Institute of Ocean Sciences, Patricia Bay, Victoria, BC).

Malcolm, J. (1979). "Studies of oil spill behaviour under ice," in Workshop on Oil, Ice and Gas, Institute for Environmental Studies, University of Toronto, Ontario.

Martin, S. (1979). "A field study of brine drainage and oil entrainment in first-year sea ice," J. Glaciol. 22(88), 473-502.

Medwin, H., and Clay, C. S. (1998). Fundamentals of Acoustical Oceanography (Academic Press, Boston, MA), pp. 41-49.

Mourad, P. D., and Williams, K. L. (1993). "Near-normal incidence scattering from rough, finite surfaces: Kirchhoff theory and data comparison for arctic sea ice," J. Acoust. Soc. Am. 94(3), 1584-1597.

NORCOR Engineering and Research Ltd. (1975). "The interaction of crude oil with arctic sea ice," Beaufort Sea Technical Report, No. 27. Beaufort Sea Project, Department of the Environment, Victoria.

Rice, S. (1952). "Mathematical analysis of random noise," in Selected Papers on Noise and Stochastic Processes, edited by N. Wax (Dover, New York), pp. 133-294.

Stanton, T. K., Chu, D., Jech, J. M., and Irish, J. D. (2010). "New broadband methods for resonance classification and high-resolution imagery of fish with swimbladders using a modified commercial broadband echosounder," ICES J. Mar. Sci. 67, 365-378.

Stanton, T. K., Chu, D., Wiebe, P. H., Martin, L. V., and Eastwood, R. L. (1998). "Sound scattering by several zooplankton groups. I. Experimental determination of dominant scattering mechanisms," J. Acoust. Soc. Am. 103(1), 225-235.

Stanton, T. K., Jezek, K. C., and Gow, A. J. (1986). “Acoustical reflection and scattering from the underside of laboratory grown sea ice: Measurements and predictions," J. Acoust. Soc. Am. 80(5), 1486-1494.

Stanton, T. K., Wiebe, P. H., Chu, D., and Goodman, L. (1994). "Acoustic characterization and discrimination of marine zooplankton and turbulence," ICES J. Mar. Sci. 51, 469-479.
Timco, G. W., and Frederking, R. M. W. (1996). "A review of sea ice density," Cold Reg. Sci. Technol. 24(1), 1-6.

Turin, G. (1960). "An introduction to matched filters," IRE Trans. Inf. Theory 6(3), 311-329.

Wadhams, P. (1976). "Oil and ice in the Beaufort Sea," Polar Rec. 18(114), 237-250.

Wadhams, P., Wilkinson, J. P., and McPhail, S. D. (2006). "A new view of the underside of arctic sea ice," Geophys. Res. Lett. 33, 1-5, doi:10.1029/ 2005 GL025131.

Weeks, W. F. (2010). On Sea Ice (University of Alaska Press, Fairbanks, AK), pp. 78-143.

Weeks, W. F., and Gow, A. J. (1978). "Preferred crystal orientations in the fast ice along the margins of the Arctic Ocean," J. Geophys. Res.: Oceans 83(C10), 5105-5121, doi:10.1029/JC083iC10p05105.

Wen, T., Garrison, G. R., Francois, R. E., Stein, R. P., and Felton, W. J. (1991). "Sound speed, reflectivity, and absorption measurements in arctic ice in 1988," Technical Report, Appl. Phys. Lab. Rep. APL-UW TR 9005.

Wilkinson, J., Maksym, T., Bassett, A. C., Lavery, A., Singh, H., Chayes, D., Elosegui, P., Wadhams, P., Ulrich-Evers, K., and Jochmann, P. (2014). "Experiments on the detection and movement of oil spilled under sea ice," in Proceedings of the HYDRALAB IV Joint User Meeting, Lisbon, Portugal (July 2-4).

Wilkinson, J., Maksym, T., and Singh, H. (2013). "Capabilities for detection of oil spills under sea ice from autonomous underwater vehicles," Technical Report, Joint Industry Program on Oil Spill Detection and Mapping in Low Visibility and Ice: Focus on Undersea Remote Sensing, 11 pp.

Wilkinson, J. P., Boyd, T., Hagen, B., Maksym, T., Pegau, S., Roman, C., Singh, H., and Zabilansky, L. (2015). "Detection and quantification of oil under sea ice: The view from below," Cold Reg. Sci. Technol. 109, 9-17.

Wilkinson, J. P., Wadhams, P., and Hughes, N. E. (2007). "Modelling the spread of oil under fast sea ice using three-dimensional multibeam sonar data," Geophys. Res. Lett. 34, 1-5, doi:10.1029/2007GL031754.

Williams, G., Maksym, T., Wilkinson, J. P., Kunz, C., Murphy, C., Kimball, P., and Singh, H. (2015). "Thick and deformed sea ice mapped with autonomous underwater vehicles," Nat. Geosci. 8, 61-67.

Williams, K. L., Garrison, G. R., and Mourad, P. D. (1992). "Experiment examination of growing and newly submerged sea ice including acoustic probing of the skeletal layer," J. Acoust. Soc. Am. 92(4), 2075-2092.

Winebrenner, D. (1992). "Acoustic backscattering from sea ice at high frequencies,” Technical Report, Appl. Phys. Lab. Rep. APL-UW TR 9017. 